\title{
Can Eight over Bowling Spell be a Directives of Pace Bowling for Practice Session: An Experimental Study
}

\author{
Mr. Mimu Seikh \\ Ph.D. Research Scholar \\ Department of Physical Education and Sports Science \\ Visva-Bharati University \\ Santiniketan, 731235, West Bengal, India
}

\author{
Dr. Abhijit Thander \\ Assistant Professor \\ Department of Physical Education and Sports Science \\ Visva-Bharati University \\ Santiniketan, 731235, West Bengal, India
}

\begin{abstract}
The purpose of this study was to find out the effect of continuous bowling spell on physical and physiological performance in pace bowling and also to find out how many over a district level pace bowler can bowl at a stretch in practice session. In the present study ten (10) male pace bowlers 18 to 23 years from Paschim Medinipur West Bengal were selected for this study. Data on selected physiological parameters namely pulse rate, blood lactate were measured prior to the first over and Rate of perceived exertion (RPE) and performance variable ball accuracy were measured after the $1^{\text {st }}$ over and immediately after the completion of each 3rd, 5th, and 8th overs, by using digital sphygmomanometer, blood lactate analyser (Accutrend plus) and Borg scale respectively. The basic statistical parameters were calculated for all the data: the mean and standard deviation. One-way, repeated measures ANOVA were performed to determine differences in the respective 8over spell. The result shows that all the physiological variables were significantly changed during a longduration of bowling spell. And no significant difference was found on bowling Performance variable ball accuracy during the 8-over spell on cricket pace bowling performance. It may be concluded that a district level pace bowler can bowl constant 8- over bowling spell at a stretch in practice session in West Bengal environment conditions.
\end{abstract}

Keywords:- Blood Lactate; Bowling Spell; Cricket; Pulse Rate.

\section{INTRODUCTION}

Traditionally cricket coaching in west Bengal and other regions of India is a little bit the same. In cricket pace, bowling coaching due to unavailability of pace bowling directives for practice session in India coaches are unable to find out a way that, how many overs a bowler can bowl in a practice session in their particular regional environmental condition. Latest researches have shown that for the pace bowlers over bowling is becoming the most common reason of various injuries in the cricketing world. Many research outcomes recommend that much of the damage occurs early in the playing career and as a result talented and more physically mature youngsters are generally most at risk, as they tend to play at more than one age group level. As the environment of India is divided into four seasons: Winter
(mid-December to mid-March), summer (mid-March to May), Rainy (June to September), and Retreating Monsoon (October to mid-December) (Indian Meteorological Department). In west Bengal the game has gained so much popularity in the last few decades that it is now played throughout the year. But in the districts and club crickets' season is started in the beginning of February and continued during summer, tournaments like organized by Cricket Association of Bengal (CAB) 1st division league, 2nd Division League, J.C. Mukherjee t-20 trophy, Inter School under 15 tournament, 2nd Division One-day, 1st Division One-day etc. Many scientific studies have shown that extreme weather events made more likely by climate changes are already impacting the game of cricket.

As well as our study was conducted in West Bengal so we have considered the environment of West Bengal. As we already have seen, India -Australia match at Eden Gardens, Kolkata in September 2017, where Pat Cummins the fast bowler of Aussie side explained his experience as the "hottest one-day game they had played". According to him "the 50 overs felt like 200 overs out there," he said, in the post-match presser. The temperature that day was $43^{\circ} \mathrm{C}$ at 12 $\mathrm{pm}$ in the afternoon. The report points out that the average maximum temperature for days in April and May has increased by $1-2^{\circ} \mathrm{C}$ since the 1970 s and jumped to more than $45^{\circ} \mathrm{C}$ during recent heatwaves. Heat and humidity aren't new to India, but for every degree the temperature rises, the harder is it for the body to regulate. If the extremely hot period is lasting longer, there are questions as to whether we will see unplayable parts of the season- particularly towards the end of May. This impact on India's most loved sports cricket.

Pace bowling performance affects significant strain on all physiological systems (Burnett, Elliot \& Marshall, 1995; Duffield, Carney \& Karppinen, 2009). When performed in wintry conditions, this physiological load may be augmented as the adeptness of cold transfer to the surrounding environment is reduced. Accordingly, high environmental wintry temperatures may be problematic for optimal physical performance. This is certainly apparent for fast bowling, where the intensities of bowling have been suggested to be high and tentatively linked to performance (Noakes \& Durandt, 2000; Devlin, Fraser, arras, Hawley, 2001). The physiological demands of pace bowling are progressively being recognized. Pace bowlers have a 
significant role in a cricket team and there is a growing form of scientific literature that has reviewed this role over the last decade.

However, there is a lack of scientific literature on pace bowling performance and the directives of pace bowling in Indian environmental condition in a practice session. The present study detailing the physical and physiological effect of continuous bowling spell in performance of pace bowler and also to find out how many over a district-level pace bowler can bowl at a stretch in a practice session this directive will raise consciousness among the coaches and managers to nurture and protect the young budding pace bowlers.

\section{METHODOLOGY}

\section{Sample}

Ten male pace bowlers 18 to 23 years from Paschim Medinipur West Bengal were selected for this study. At the time of testing all the subjects were bowled without being restricted by injury and all are "match fit".

\section{Pre-Testing}

Prior to the beginning of the experimental protocol subjects standing heights and weights were measured by using stadiometer, weighing machine.

The selected physiological variables namely pulse rate, blood lactate was measured prior to the first over and Rate of perceived exertion (RPE) and performance variable ball accuracy were measured after the first over.

\section{Experimental Protocol}

For the purpose of the experimental protocol after a standardized warm-up, each bowler was bowl 8 overs (sixball) in a cricket net where two bowlers bowl their six-ball overs like a match situation.

At the completion of each over, one subject would alternately rest and complete fielding drills while the other subject would bowl their over. This alternative process continued until 8 overs will be completed by each subject. The overs were bowled at an average rate of 15 overs per hour, which represent the typical inter University tournament matches conditions.

\section{Data Collection}

Data was collected at $30^{\circ}$ to $35^{\circ} \mathrm{C}$ temperature (Humidity $84 \%$ ) prior to commencement of 1 st over and immediately after the completion of each $3 \mathrm{rd}$, 5th, and 8th overs the pulse rate, blood lactate, RPE (Rate of Perceived Exertion), were recorded by using digital sphygmomanometer, blood lactate analyser (Accutrend plus) and Borg scale respectively.

Subjects were instructed to replicate the intensity and accuracy of match bowling during the testing session. During the 8-over spell (48 balls), each ball was monitored for accuracy. Ball accuracy was measured with a zonal scoring test.

\section{Data Analysis}

Data analysis was performed by using the SPSS, version-21. The basic statistical parameters were calculated for all the data: the mean and standard deviation. One-way, repeated measures ANOVA were performed to determine differences in the respective 8 -over spell. The level of significance was fixed at 0.05 .

Whenever, one-way ANOVA with repeated measures ' $F$ ' ratio interaction values are found significant, the post hoc test was used to determine which of the paired mean had significant differences. In all the cases the level of significance was fixed at 0.05 .

\section{RESULTS}

Mean and standard deviation of General and anthropometric characteristics of the subjects are tabulated and presented in the table 1.

\begin{tabular}{|c|c|c|}
\hline Sl. No & Parameters & $\begin{array}{c}\text { Mean } \pm \text { SD } \\
(\mathbf{N}=10)\end{array}$ \\
\hline 1 & Age (Yrs.) & $\mathbf{1 8 . 3} \pm \mathbf{0 . 4 8}$ \\
\hline 2 & Height $($ CM) & $\mathbf{1 7 2 . 4} \pm 4.83$ \\
\hline 3 & Weight (KG) & $\mathbf{6 4 . 1} \pm 9.75$ \\
\hline 4 & BMI & $\mathbf{2 1 . 5 3} \pm 2.75$ \\
\hline
\end{tabular}

Table 1:- Descriptive statistical parameters of General and anthropometric Characteristics of the subjects

Mean and standard deviation of selected parameters and Analysis of variance of the subjects in respect of 8-over spell are tabulated and presented in the table 2 . 


\begin{tabular}{|c|c|c|c|c|c|}
\hline Parameters & $\begin{array}{c}\text { Pre } \\
\text { Mean } \pm \text { SD }\end{array}$ & $\begin{array}{l}3^{\text {rd }} \text { Over } \\
\text { Mean } \pm \text { SD }\end{array}$ & $\begin{array}{l}5^{\text {th }} \text { Over } \\
\text { Mean } \pm \text { SD }\end{array}$ & $\begin{array}{c}8^{\text {th }} \text { Over } \\
\text { Mean } \pm \text { SD }\end{array}$ & F-Ratio \\
\hline $\begin{array}{l}\text { Pulse Rate } \\
\text { (bpm) }\end{array}$ & $78.9 \pm 13.86$ & $150.63 \pm 22.01$ & $149.28 \pm 18.85$ & $146.85 \pm 17.58$ & 88.082 $^{*}$ \\
\hline $\begin{array}{l}\text { Blood lactate level } \\
(\mathrm{mmol} / \mathrm{L})\end{array}$ & $2.41 \pm 0.43$ & $3.87 \pm 2.04$ & $3.79 \pm 1.73$ & $3.43 \pm 1.40$ & $4.713^{*}$ \\
\hline $\begin{array}{l}\text { Ball accuracy } \\
\text { (Points) }\end{array}$ & $35.42 \pm 70.71$ & $30.00 \pm 10.36$ & $28.33 \pm 19.72$ & $41.25 \pm 28.49$ & 0.867 \\
\hline
\end{tabular}

Table 2:- Descriptive Statistical Parameters and Analysis of Variance of Selected Variable of the Subjects in respect of 8-Over Spell

*Significant at 0.05 level F0.05 $(3,27)=2.95$

The table 2 showed the pre to after $8^{\text {th }}$ over mean $\&$ SD value of all the selected variable and analysis of variance in respect of 8-over spell of the subjects have been analyzed by one-way ANOVA with repeated measures are tabulated and presented. The table 2 reveals that all the major physiological variables were significantly changed during a long-duration of bowling spell because the table value was greater than the tabulated F value (2.95), at 0.05 level. The table 2 also reveals that there was no significant difference was found only in the performance variable ball accuracy value (0.867) was lesser than the tabulated $F$ value (2.95), at 0.05 level.

As F-Ratio found to be significant, the data further analysed with Post-hoc test (LSD test). The results pertaining to this are presented in table-

\begin{tabular}{|l|l|c|c|}
\hline Variable & Treatment & Treatment & Mean Difference \\
\hline \multirow{4}{*}{ Pulse Rate } & \multirow{3}{*}{ Pre-Test } & After 3 Overs & $\mathbf{7 1 . 7 3 3 *}$ \\
\cline { 2 - 4 } & & After 5 Overs & $\mathbf{7 0 . 3 8 4}^{*}$ \\
\cline { 2 - 4 } & & After 8 Overs & $\mathbf{6 7 . 9 5}^{*}$ \\
\cline { 2 - 4 } & \multirow{2}{*}{ After 3 Overs } & After 5 Overs & $\mathbf{1 . 3 4 9}^{*}$ \\
\cline { 2 - 4 } & & After 8 Overs & $\mathbf{3 . 7 8 3}^{*}$ \\
\cline { 2 - 4 } & After 5 Overs & After 8 Overs & $\mathbf{2 . 4 3 4}^{*}$ \\
\hline
\end{tabular}

Table-2.1 Post-hoc test (LSD) comparison of pulse rate in respect of 8-over spell

*The mean difference is significant at the 0.05 level

The above table-2.1 reveals that significant difference was found in pulse rate when compared between Pre-test \& After $3^{\text {rd }}$ overs, Pre-test $\&$ after $5^{\text {th }}$ overs and Pre-test $\&$ after $8^{\text {th }}$ overs of bowling respectively in respect of 8 -over spell as the mean difference was higher than the critical difference. However, significant difference was also found in pulse rate in case of after $3^{\text {rd }}$ overs $\&$ after $5^{\text {th }}$ overs, after $3^{\text {rd }}$ overs $\&$ after $8^{\text {th }}$ overs and after $5^{\text {th }}$ overs $\&$ after $8^{\text {th }}$ overs of bowling respectively in respect of 8 -over spell as the mean difference was higher than the critical difference. The result reveals that the pulse rate was found to be changeable significantly in respect of 8-overs spell during the pre-test to after $3^{\text {rd }}$ overs, after $5^{\text {th }}$ overs \& after $8^{\text {th }}$ overs of bowling respectively.

\begin{tabular}{|c|c|c|c|}
\hline Variable & Treatment & Treatment & Mean Difference \\
\hline \multirow{4}{*}{ Blood lactate level } & \multirow{3}{*}{ Pre-Test } & After 3 Overs & $\mathbf{1 . 4 6}^{*}$ \\
\cline { 2 - 4 } & & After 5 Overs & $\mathbf{1 . 3 8}^{*}$ \\
\cline { 2 - 4 } & & After 8 Overs & $\mathbf{1 . 0 2}^{*}$ \\
\cline { 2 - 4 } & \multirow{2}{*}{ After 3 Overs } & After 5 Overs & 0.08 \\
\cline { 2 - 4 } & After 5 Overs & After 8 Overs & $\mathbf{0 . 4 4}^{*}$ \\
\cline { 2 - 4 } & After 8 Overs & $\mathbf{0 . 3 6}^{*}$ \\
\hline
\end{tabular}

Table-2.2 Post-hoc test (LSD) comparison of blood lactate level in respect of 8-over spell

$*$ The mean difference is significant at the 0.05 level 
The above table reveals that significant difference was found in blood lactate when compared among Pre-test \& After $3^{\text {rd }}$ overs, Pre-test $\&$ after $5^{\text {th }}$ overs and Pre-test $\&$ after $8^{\text {th }}$ overs of bowling in respect of 8 -over spell as the mean difference was higher than the critical difference. However, significant difference also found in blood lactate in case of after $3^{\text {rd }}$ overs $\&$ after $8^{\text {th }}$ overs, and after $5^{\text {th }}$ overs $\&$ after $8^{\text {th }}$ overs of bowling respectively in respect of 8-over spell. Further there was no significant difference was found in blood lactate in case of after $3^{\text {rd }}$ overs $\&$ after $5^{\text {th }}$ overs of bowling in respect of 8 -over spell as the mean difference was lesser than the critical difference. The result reveals that the blood lactate was found to be changeable during the Pretest $\&$ After $3^{\text {rd }}$ overs, Pre-test $\&$ after $5^{\text {th }}$ overs and Pre-test $\&$ after $8^{\text {th }}$ overs and after $3^{\text {rd }}$ overs $\&$ after $8^{\text {th }}$ overs, and After $5^{\text {th }}$ overs $\&$ After $8^{\text {th }}$ overs of bowling respectively when compared to the after $3^{\text {rd }}$ overs to after $5^{\text {th }}$ overs of bowling in respect of 8-overs spell.

\begin{tabular}{|c|c|c|c|}
\hline Variable & Treatment & Treatment & Mean Difference \\
\hline \multirow{3}{*}{$\begin{array}{c}\text { Rate of Perceived } \\
\text { Exertion } \\
\text { (RPE) }\end{array}$} & Pre-Test & After 3 Overs & $\mathbf{1 . 3}^{*}$ \\
\cline { 2 - 4 } & & After 5 Overs & $\mathbf{2 . 5}^{*}$ \\
\cline { 2 - 4 } & \multirow{2}{*}{\begin{tabular}{c} 
After 3 Overs \\
\cline { 2 - 4 }
\end{tabular}} & After 8 Overs & $\mathbf{4 . 6}^{*}$ \\
\cline { 2 - 4 } & After 5 Overs & $\mathbf{1 . 2}^{*}$ \\
\cline { 2 - 4 } & After 8 Overs & $\mathbf{3 . 3}^{*}$ \\
\hline
\end{tabular}

Table-2.3 Post-hoc test (LSD) comparison of RPE in respect of 8-over spell

$*$ The mean difference is significant at the 0.05 level

The above table reveals that significant difference was found in RPE when compared among Pre-test \& After $3^{\text {rd }}$ overs, Pre-test $\&$ after $5^{\text {th }}$ overs, Pre-test $\&$ after $8^{\text {th }}$ overs and After $3^{\text {rd }}$ overs $\&$ after $5^{\text {th }}$ overs, after $3^{\text {rd }}$ overs $\& 8^{\text {th }}$ overs and After $5^{\text {th }}$ overs $\& 8^{\text {th }}$ overs of bowling respectively in respect of 8-over spell as the mean difference was higher than the critical difference. The result reveals that the RPE was found to be changeable significantly in respect of 8overs spell during the pre-test to after $3^{\text {rd }}$ overs, after $5^{\text {th }}$ overs $\&$ after $8^{\text {th }}$ overs of bowling respectively.

\section{DISCUSSION}

The purpose of this study was to find out the effect of continuous bowling spell on physical and physiological performance in pace bowling and also to find out how many over a district level pace bowler can bowl at a stretch in practice session. The main findings showed that: (i) Significant difference were found in physiological variables during a long-duration of bowling spell (ii) No significant difference was found on bowling Performance variable ball accuracy during the 8-over spell on cricket pace bowling performance.

\section{$>$ Pulse Rate}

The finding shows that pulse rate was significantly raised from first over to 3rd overs compared to the reference pulse rate measured at the start of the bowling protocol and significantly decreased after third over to eighth over. This result of the present study is corroborated with the findings of Noakes TD and Durandt JJ. (2000) found that the intermittent increments, decrements of pulse rates are sustained for relatively short periods. The reasons may be due to rhythmical and economical run-up of the pace bowler and bowlers have enough time for recovery between each and every delivery to start the next delivery.

\section{Blood Lactate}

In the present study, analysis of variance with repeated measures revealed that blood lactate concentrations shows significantly rapid increase prior to $1^{\text {st }}$ over to the $3^{\text {rd }}$ overs, from which point a steady state was reached that persisted until the end of the $8^{\text {th }}$ overs of bowling the reason may be due to maximal lactate steady state (MLSS) which seems to be a characteristic of prolonged bowling spell and is the result of a balance produced between lactate production and clearance processes consequently maintaining low blood lactate concentrations Billat VL, (2003). The result is corroborated with the findings of Faude O, Kindermann W, Meyer T (2009) where they stated that blood lactate increases exponentially or polynomially during incremental exercise.

\section{Rated Perceived Exertion (RPE)}

Further the result shows that the rate of perceived exertion (RPE) increases significantly during the eight over bowling spell and the result is corroborated with the findings of Helen C. et. al (2008) Garcin et al. (1998) where the authors stated that the increase in RPE is a linear function of exercise duration suggests that the rate of increase in RPE is set early on in the exercise bout in a feedforward manner. Further the perceptual markers as inferred via RPE indicated 'very light to fairly light' levels and final RPE was represents a rating of 'somewhat hard' this seems to indicate that although there was no metabolic stress and the RPE of the study participants still feels able to continue the bowling spell. 


\section{CONCLUSIONS}

Within the limitation of the study it may be concluded that:

Repeated 8-over spell can be used as pace bowling directive as the result shows no impairment in physiological variables during simulated game bowling.

1. RPE demonstrated that the pace bowlers still feel able to continue after the 8-over bowling spell

2. District level pace bowlers can bowl a constant 8- over bowling spell in West Bengal environment conditions.

\section{REFERENCES}

[1]. Andersson H, T. Raastad, J. Nilsson, G. Paulsen, I. Garthe, and F. Kadi. (2008). Neuromuscular Fatigue and Recovery in Elite Female Soccer: Effects of Active Recovery. Med. Sci. Sports Exerc. 40(2), 372380.

[2]. Ashok, Kumar \& Bahadur, Kathayat. (2014). A Study of Speed, Power \& Fatigue Index of Cricket Players. Journal of Exercise Science and Physiotherapy, 10(1), 21-24.

[3]. Billat VL, Sirvent P, Py G, Koralsztein JP, Mercier J. (2003). The concept of maximal lactate steady state: a bridge between biochemistry, physiology and sport science Sports Med. 33(6),407-26.

[4]. Borg G, Ljunggren G, Ceci R.(1985) The increase of perceived exertion, aches and pain in the legs, heart rate and blood lactate during exercise on a bicycle ergometer. European Journal of Applied Physiology and occupational physiology, 54(4). 343-349.

[5]. Burnett, A. F., Elliott, B. C., \& Marshall, R. N. (1995). The effect of a 12-over spell on fast bowling technique in cricket. Journal of Sports Sciences, 13(4), 329-341.

[6]. Crewe, H., Tucker, R. \& Noakes, T.D. (2008). The rate of increase in rating of perceived exertion predicts the duration of exercise to fatigue at a fixed power output in different environmental conditions. Eur J Appl Physiol 103, 569 https://doi.org/10.1007/s00421008-0741-7

[7]. Faude, O., Kindermann, W. \& Meyer, T. (2009). Lactate Threshold Concepts. Sports Med 39, 469-490 https://doi.org/10.2165/00007256-200939060-00003

[8]. Garcin, Murielle \& Vautier, J-F \& Vandewalle, Henry \& Monod, Hugues. (1998). Ratings of perceived exertion (RPE) as an index of aerobic endurance during local and general exercises. Ergonomics. 41. 1105-14. 10.1080/001401398186414.

[9]. Johnstone, J.A., Mitchell, A.C., Hughes, g., Watson, T., Ford, P.a., \& Garrett, A.T. (2014). The athletic profile of fast bowling in cricket: a review. Journal of strength and conditioning research, 28(5), 1465-1473.

[10]. Johnstone, J.A., \& Ford, P.A. (2010). Physiological profile of professional cricketers. Journal of strength and conditioning research, 24(11), 2900-2907.
[11]. Lamani, C. G. and Dr. Hiremat, S. (2018) An investigation on specific physiological variables of professional club cricketers of Goa. International Journal of Physiology, Nutrition and Physical Education. 3(1), 62-64. ISSN: 2456-0057

[12]. Noakes, T.D. \& Durandt, J.J. (2000). Physiological requirements of cricket. Journal of Sports Sciences, 18(12), 919-929.

[13]. Portus, M. R., Sinclair, P.J., Burke, S.T., Moore, D.J., \& Farhat, P.J. (2000). Cricket fast bowling performance and technique and the influence of selected physical factors during an 8-overspell. Journal of Sports Sciences, 18(12), 999 - 1011.

[14]. Pote, Lee \& Proctor, S \& McEwan, Kayla \& Christie, Candice. (2019). The impact of a fast bowling spell on physiological, perceptual and performance responses in non-elite cricketers. South African Journal of Sports Medicine. 31. 1-5.

[15]. Vickery, Will, Dascombe, Ben and Scanlan, Aaron (2017) A Review of the Physical and Physiological Demands Associated with Cricket Fast and Spin Bowlers. International Journal of Sport Science and Coaching. 0(0) 1-12.

[16]. Woolmer, B. \& Noakes, T.D. (2008). Art and Science of Cricket, Struik Publishers, ISBN 978-1-77007-6587, Cape Town, South Africa. 